\title{
A repaired $S_{1}-R_{2}$ and $S_{2}-R_{1}$ transfer surface'
}

JOHN P. HOUSTON

\section{Abstract}

A surface was described which summarized the transfer effects expected in two-list paradigms varying in $\mathrm{S}_{1}-\mathrm{R}_{2}$ and $\mathrm{S}_{2}-\mathrm{R}_{1}$ similarity when the first-list units were repaired in the second list. According to the surface, negative transfer should increase as $S_{2}-R_{1}$ similarity increases. This increase should be greater when $S_{1}-R_{2}$ similarity is high than when it is low.

\section{Problem}

The literature contains at least three surfaces relating degree and direction of transfer to interlist similarity. The first of these, Osgood's (1949) well known surface, relates transfer to the similarity between first and second-list stimuli $\left(\mathrm{S}_{1}-\mathrm{S}_{2}\right)$ and to the similarity between first and second-list responses $\left(\mathbf{R}_{\mathbf{1}^{-}}\right.$ $R_{2}$ ). A second surface, which is concerned with Osgood's paradigms in which the second-list S-R pairings do not correspond to the first-list pairings, has been developed and tested by Dallet (1965). According to this surface, maximum negative transfer will obtain in the $A-B, A-B_{r}$ paradigm. As the similarity between stimuli and the similarity between responses decreases in these noncorresponding paradigms negative transfer will tend to decrease. The third surface (Houston, 1964; 1965a; 1965b), in contrast to the Dallett and Osgood surfaces, relates transfer to the similarity between first-list stimuli and second-list responses $\left(S_{1}-R_{2}\right)$ and to the similarity between second-list stimuli and first-list responses $\left(S_{2}-R_{1}\right)$. The present paper is concerned with the development of a fourth surface, one which summarizes transfer effects expected in the Houston (1964) paradigms when repairing occurs between the two lists. The analysis leading to the construction of this surface draws heavily upon the kind of treatment that Dallett (1965) has given to the repaired Osgood paradigms.

\section{The Surface}

Both the Houston (1964) and the proposed repairing surfaces are contained in Fig. 1. The lower of the two is the proposed repairing surface. The width of the surfaces, labeled $S_{2}-R_{1}$, refers to the similarity between second-list stimuli and first-list responses. The length of the surfaces, labeled $S_{1}-R_{2}$, refers to the similarity between first-list and second-list responses. Both dimensions extend from identity, labeled 1 , to neutrality, labeled 0 . The A-B, C-D paradigm represents the control condition against which transfer in the other paradigms is judged. The upper, or non-repaired, surface indicates that transfer will be minimal when $S_{2}-R_{1}$ similarity is minimal. As $\mathrm{S}_{2}-\mathrm{R}_{1}$ similarity increases transfer will increase. This increase will be in the positive direction when $S_{1}-R_{2}$ similarity is high and in the negative direction when $S_{1}-R_{2}$ similarity is low. These predictions are determined by the assumption that backward first-list associations will either mediate or compete with the formation of forward second-list associations. Data supporting the predictions of the upper surface are reported by Houston (1965a; 1965b).

The lower surface differs from the upper surface in that the lower pardigms represent situations in which the first-list units are repaired in the second list. For example, in the $\mathrm{A}-\mathrm{B}, \mathrm{B}-\mathrm{A}_{\mathrm{r}}$ paradigm the $\mathrm{A}$ and $\mathrm{B}$ units from the first list are used in the second list but they are repaired. In the $\mathrm{A}-\mathrm{B}, \mathrm{B}-\mathrm{A}_{\mathrm{r}}^{\prime}$ paradigm similar $\mathrm{A}$ and $A^{\prime}$ units are not paired with the same $B$ units. In the $A-B, B^{\prime}-A_{r}$ situation $B$ and $B^{\prime}$ units are not paired with the same A units. The two surfaces in Fig. 1 coincide when $S_{1}-R_{2}$ similarity is minimal and when $S_{2}-R_{1}$ similarity is minimal. Along these edges, which have been verified by Houston $(1965 \mathrm{a} ; 1965 \mathrm{~b})$, there is no difference between the definition of a repaired and a nonrepaired paradigm. The proposed lower surface predicts that, when $\mathrm{S}_{2}-\mathrm{R}_{1}$ similarity is minimal, transfer will be minimal. As $\mathrm{S}_{2}-\mathrm{R}_{1}$ similarity increases negative transfer will increase. This increase will be greater when $S_{1}-R_{2}$ similarity is high than when it is low.

\section{Diseussion}

The shape of the proposed surface is determined by a consideration of the effects of three important components of verbal PA transfer. These factors, sum-

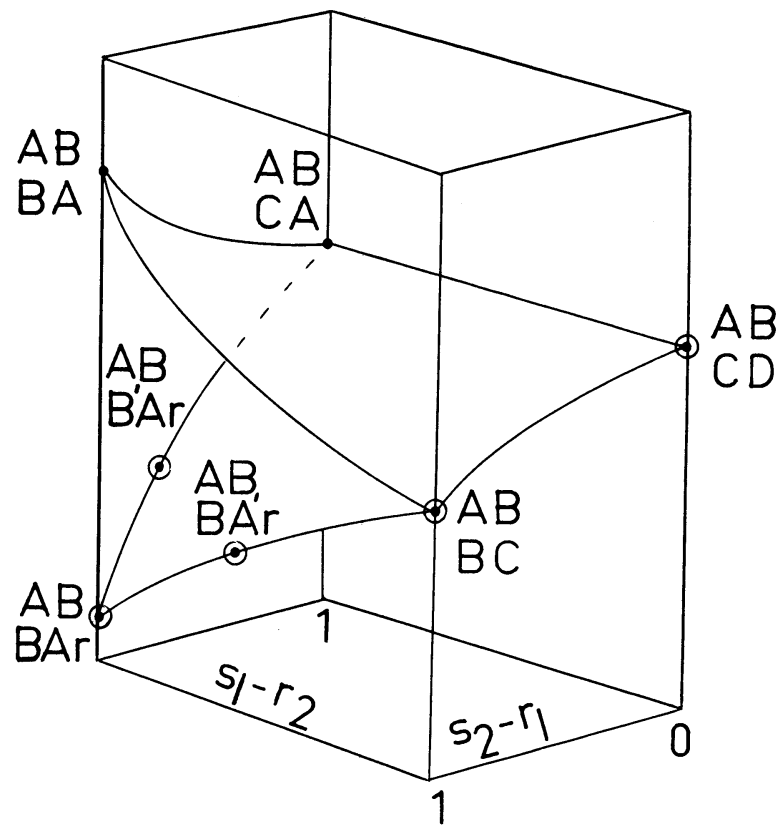

Fig. 1. The non-repaired and the proposed repaired transfer surfaces. 
marized by Dallett (1965), include stimulus and response familiarization, list differentiation and associative interference. Familiarization effects refer to the fact that first-list experience with the second-list stimuli and responses may facilitate second-list learning. Increases in second-list difficulty associated with losses in list differentiation, or the ability to distinguish between lists, are correlated with increases in the similarity between the lists. Associative interference, presumed to be maximal when successive associations form an A-B, A-C relationship, results from the competition of prior associations with the formation of new associations. In the present analysis two principal sources of this kind of interference are to be found. The backward first-list associations may compete with the formation of the forward second-list associations and the forward firstlist associations may compete with the formation of the backward second-list associations.

The effects of variations in $S_{2}-R_{1}$ and $S_{1}-R_{2}$ similarity upon these three components of transfer will be considered separately. When $S_{2}-R_{1}$ similarity is increased, regardless of the degree of $S_{1}-R_{2}$ similarity, familiarity with the second-list stimuli probably increases, list differentiation decreases because of the increasing similarity of the lists, and associative interference increases because the relationship between the backward first-list and forward second-listassociation approaches the extinctive A-B, A-C relationship. Depending, of course, upon the relative importance of these factors, a net gain in negative transfer might be expected as $\mathrm{S}_{2}-\mathrm{R}_{1}$ similarity increases. Two of the factors, decreasing list differentiation and increasing interference, suggest an increase in second-list difficulty while only one, stimulus familiarity, suggests easier second-list learning.

Turning now to a consideration of the effects of increases in $\mathrm{S}_{1}-\mathrm{R}_{2}$ similarity, regardless of the degree of $\mathrm{S}_{2}-\mathrm{R}_{1}$ similarity, one might expect second-list response familiarity to increase, list differentiation to decrease, and associative interference to increase in that the forward first-list and backward second-list associations approach the extinctive A-B, A-C relationship. Once again one might expect a net gain in negative transfer.

Thus, independent increases in $S_{1}-R_{2}$ and $S_{2}-R_{1}$ similarity may be expected to yield increases in negative transfer. The shape of the proposed surface in Fig.1 merely expresses the combination of these two predictions. Simultaneous variations in $S_{1}-R_{2}$ and $S_{2}-R_{1}$ similarity may be expected to yield increasing negative transfer as $\mathrm{S}_{2}-\mathrm{R}_{1}$ similarity increases with the increase becoming greater as $\mathrm{S}_{1}-\mathrm{R}_{2}$ similarity increases. Each point on the surface reflects a balance of these various influences. For example, in the A-B, B-A paradigm, stimulus and response familiarity is high but list differentiation is very low and both kinds of associative interference are operative. Note should be taken of the fact that the surface predicts no transfer in the A-B, $\mathrm{C}-\mathrm{A}$ paradigm. According to the above analysis one might expect negative transfer in this paradigm but Houston (1964a) has failed to confirm this prediction.

Of course considerable variation in the shape of the surface may occur when different types of procedures and materials are employed. For example, little or perhaps even positive transfer might be expected in the $\mathrm{A}-\mathrm{B}, \mathrm{B}-\mathrm{A}_{\mathrm{r}}$ paradigm when the materials are of very low meaningfulness. Thus, the mnemonic function of the surface should perhaps be limited to situations involving materials of relatively high meaningfulness.

\section{References}

Dallett, $\mathbf{K}$ M A transfer surface for paradigms in which second-list S-R pairings do not correspond to first-list pairings Submitted to J. verbal Learn. verbal Behav.

Houston, J P Verbal transfer and interlist similarities, Psychol. Rev., 1964, 71, 412-414.

Houston, J P. Verbal transfer as a function of $S_{1}-R_{2}$ and $S_{2}-R_{1}$ interlist similarity. J. exp. Psychol., in press

Houston, J. P. Verbal transfer as a function of the similarity between first-list stimuli and second-list responses Submitted to $J$. verbal Learn. verbal Behav.

Osgood, C. E. The similarity paradox in human learning: A resolution. Psychol. Rev., 1949, 56, 132-143.

\section{Note}

1. This work was supported by a grant from the National Institute of Mental Health, Public Health Service (MH 11199-01). 